\title{
P186: Infection control plan management in primary care
}

\author{
I Neves, F Vieira*, D Peres, I Devesa, V Alves \\ From 2nd International Conference on Prevention and Infection Control (ICPIC 2013) \\ Geneva, Switzerland. 25-28 June 2013
}

\section{Introduction}

There was a significant shift in healthcare delivery from the acute, inpatient hospital setting to a variety of ambulatory and community-based settings. This transition of healthcare has demonstrated the need for understanding and implementation of infection prevention guidance [1] Portuguese National Infection Control Program includes in its objectives the community and ambulatory settings $[2,3]$.

\section{Objectives}

Implementation and monitoring of an Infection Control Plan in a community-based setting (with several units), part of a Local Health Unit (which includes primary, acute and rehabilitation care).

\section{Methods}

Application of Demming cycle (Plan, Do, Check; Act) in a perspective of continuous improvement according to the institution's Quality Management System [4].

\section{Results}

The Infection Control Unit, in collaboration with link professionals (doctor and nurse in each unit), implements the following strategy: (PLAN) Draw an Infection Control Plan approved by management. Example (i): create the conditions for hand hygiene through scheduled audits. Example (ii): monitoring of good practice, identifying performance critical areas. (DO) Implementation of the activities according to Plan schedule. Example (i): audits, with feed-back to health professionals. Example (ii): scheduled visits to identify areas for improvement. (CHECK) Check compliance of Plan objectives. Example (i): degree of implementation of the planned audits. Example (ii): Multidrug-resistant organisms monitoring (epidemiological surveillance system based on laboratory results); (ACT) Implementation of corrective measures to the initial Plan. Example (i): reprogramming audits not conducted. Example (ii): professionals training directed to good practice (based on critical areas identified and surveillance results).

\section{Conclusion}

Application of a strategy based on Demming cycle allows successful implementation and monitoring of an Infection Control Plan in a community based setting. Primary care still needs the development of specific indicators.

\section{Disclosure of interest}

None declared.

Published: 20 June 2013

References

1. CDC: Guide to Infection Prevention in Outpatient Settings. Atlanta: CDC 2011.

2. PNCl: Portuguese National Infection Control Plan. Lisbon: Direção-Geral de Saúde; 2007.

3. Health Regulation Document No. 20/DSQC/DSC - Infection Control Plan for Primary Care.

4. Quality Standard ISO 9001:2008 - Requirements for Quality Management Systems.

doi:10.1186/2047-2994-2-S1-P186

Cite this article as: Neves et al:: P186: Infection control plan management in primary care. Antimicrobial Resistance and Infection Control 2013 2(Suppl 1): P186. 